\title{
Investigation of the Impact of Hot Forming the Properties of Seamless Steel Bottles for Liquefied Gases
}

\author{
Vlatko MARUŠIĆ, Srbislav ALEKSANDROVIĆ, Bogdan NEDIĆ, Andrijana MILINOVIĆ
}

\begin{abstract}
Mechanical tests were performed on samples prepared from the body and the neck of bottles made of seamless tube, steel 34CrMo4. Plastic material flow curves were taken from tensile tests on samples which were made from tubes and finished bottles. Deformation hardening intensity is calculated, and propensity towards brittle fracture is estimated on the basis of the ratio of total elongation and elongation at maximum load. Compared to the samples of quenched and tempered bottle body, quenched and tempered bottle neck samples indicate that characteristics of strength are almost unchanged with an increase in the minimum strain at the destruction from $12,8 \%$ to $15,1 \%$. It was concluded that the results of the plastic material flow can serve as a preliminary indication of anomalies that could contribute to unsatisfactory results of the burst test.
\end{abstract}

Keywords: hot forming; investigation; properties; seamless bottles; tensile test

\section{INTRODUCTION}

$34 \mathrm{CrMo} 4$ steel is construction steel used in many applications (automotive and aircraft components such as crankshafts, axle arbors, tyres, forgings, wind turbines, mining equipment) due to its favourable balance of strength, toughness and wear resistance in extreme working conditions. Aforementioned balance of properties, especially high strength, resistance and ductility which are important for good performances at high pressures, also ensures a widespread application in manufacturing of high pressure steel cylinders and vessels [1-3]. 34 CrMo4 steel achieves the best mechanical properties after proper heat treatment, hence many researchers have investigated influence of cooling rate on microstructure and properties. Kučera [4] revealed that the most favourable and balanced mechanical properties (tensile strength, notch toughness and elongation) as well as grain size were achieved by quenching and tempering treatments applied after the hot forming. Investigation of different heat treatment modes determined that the best result in terms of the best ratio of tensile properties vs. balanced and high notch toughness is achieved by controlled cooling process and tempering at $470{ }^{\circ} \mathrm{C} /$ air [1]. Since $34 \mathrm{CrMo} 4$ is suitable for thermomechanical processing, some researchers deal with hot deformation behaviour of this steel. Nürnberger et al. [5] characterised the transformation behaviour of various heat-treatable steels, through deformation dependent continuous cooling transformation diagrams. Influence of deformation on transformation behaviour was established in a way that martensite start temperature increases with deformation.

It is also found that the influence of deformation on value of microstructural hardness is smaller compared to one established through variation in cooling rates. Sajadi et al. [3] examined the impact that hot deformation parameters (temperature and strain rate) have on processes of dynamic restoration of $34 \mathrm{CrMo} 4$ steel. They established the mean activation energy of hot deformation and determined relationship between the peak stress, deformation temperature and strain rate through empirical expression. Expression showing relationship between deformation temperature and strain rate was also derived.
During metal forming of seamless steel tube, bottom and neck of bottle are plastically deformed at elevated temperature. Because of the specifics of application, especially the working pressure of 200 bar (bottles for oxygen, nitrogen, argon, mixtures of argon and carbon dioxide, hydrogen), seamless steel tubes should meet the prescribed requirements in terms of mechanical properties [6]. After the hot forming, bottles are subsequently heat treated by quenching and tempering process (QT), therefore it is necessary to test mechanical properties on specimens sampled from bottles in order to determine if they meet the requirements of standard. Static tensile test is being performed in order to determine flow curves, strength and elongation. Deformation hardening intensity is estimated through comparison of calculated values of tensile strength and yield strength while tendency towards brittle fracture is evaluated through ratio of total elongation and elongation at maximum load.

\section{SOME SPECIFICS IN BOTTLES MANUFACTURING AND CONTROL}

In this paper specifics of making $\varnothing 229 \mathrm{~mm}$ bottles has been analised. Fig. 1 shows manufacturers drawing of one seamless steel bottle [7]. Requirements for material (tubes) [8] and the general technical data for these bottles are: material $34 \mathrm{CrMo} 4$ as declared $(\mathrm{C}=0,30 \div 0,37 ; \mathrm{Si}=0,15$ $\div 0,35 ; \mathrm{Mn}=0,5 \div 0,8 ; \mathrm{P}$ and $\mathrm{S} \max .0,02 ; \mathrm{Cr}=0,9 \div 1,2$ and $\mathrm{Mo}=0,15 \div 0,3$ ); required minimum properties of finished bottles $R_{\mathrm{e}}=840 \mathrm{MPa} ; R_{\mathrm{m}}=990 \mathrm{MPa} ; A_{5}=14 \%$; main technical data for bottles: volume $50 \mathrm{l}$; working pressure 200 bar; test pressure 300 bar; minimum wall thickness 5,4 mm; length $1510 \mathrm{~mm}(+15 /-10)$; empty bottle weight $56,5 \mathrm{~kg}(+5,85 /-4,52)$.

Technology of production of bottles from tubes on CNC machines is shown in Fig. 2 [9]. After acceptance control of seamless tubes (1), the process is divided into these phases: closing (2) and forming of the bottom (3), control check (4), neck forming (5), heat treatment of bottle (6), neck tapping (7) and control (8), blast cleaning (9), control (10); test under pressure (11), bottle labelling (12) and anti-corrosion protection (13). After finnishing that last phase, bottle is ready to be delivered to customer. 


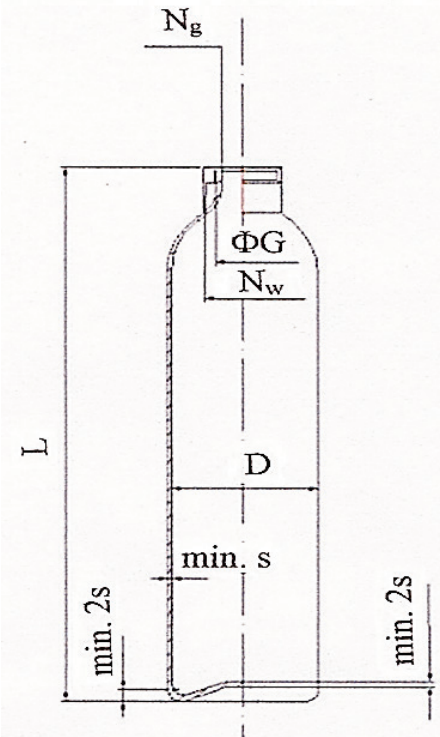

Figure 1 Characteristics of seamless steel bottle, dimension of bottles $\varnothing 229$ $\mathrm{mm}$ [7]

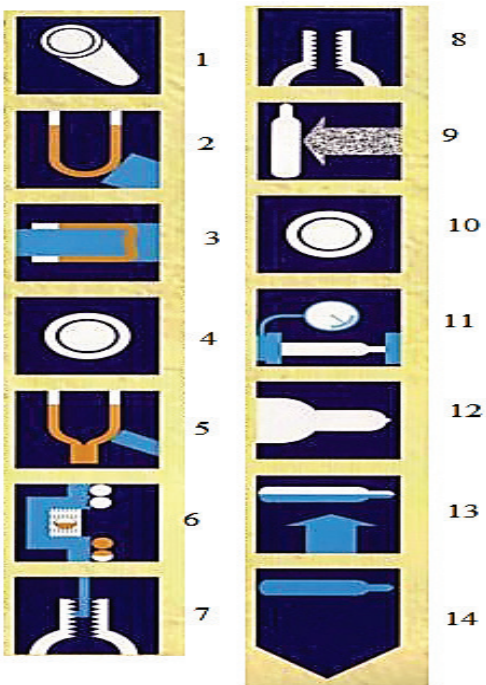

Figure 2 Overview of the technological process of making bottles [9]

\subsection{Closing the Bottom and Forming the Bottle}

Heating is performed in a way as to put one end of the tube into the gas chamber furnace. Based on experience, heated length is about $150 \mathrm{~mm}$ when closing the bottom of the tube, and about $190 \mathrm{~mm}$ when forming the bottles neck. The tube was held at a temperature between $1223^{\circ} \mathrm{C}$ and $1273{ }^{\circ} \mathrm{C}$ for a 3 minute period. Once heated, the tube is taken out of the furnace and transported to the Spinning machine where forming takes place according to a predetermined program. After forming, the bottle is disengaged from the chuck, and controled visually.

\subsection{Heat Treatment of Bottles - Quenching and Tempering}

Formed and visually controlled bottle is sent into the flow furnace for quenching. After holding at temperature of $\vartheta_{a} \approx 870{ }^{\circ} \mathrm{C} / 5^{\prime}$, bottle is quenched in an emulsion, and transferred to the electric chamber flow furnace for tempering afterwards. The duration of the process from entering the bottle until exit from the furnace is about 55 minutes.

\subsection{Burst Test}

Burst test is performed after heat treatment, one in every 200 bottles is being examined [9]. The test (in the presence of authorised inspecting body) consists of filling the bottle with water and pressurizing it to the pressure equal to 1,5 times the working pressure. As the bottles for highly liquefied gases (oxygen, nitrogen, argon, mixtures of argon and carbon dioxide, hydrogen), since their operating pressure is 200 bar, test is conducted by pressurizing them at 300 bar. Bottles are being pressurized until burst, where the body of the bottle must burst in the "fishbone" manner (tearing in small "shrapnel" parts is not allowed). The characteristic shape of fractured bottle after the burst test is shown in Fig. 3.

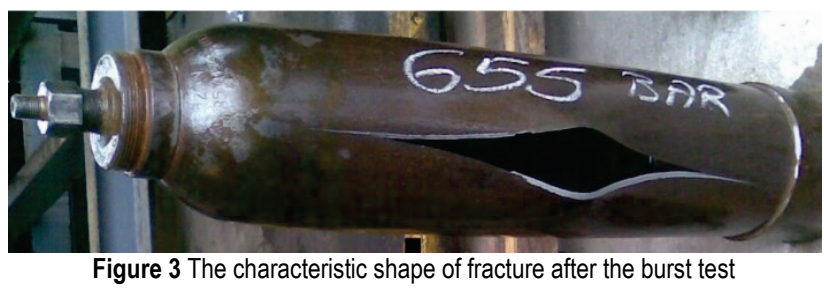

If a bottle does not meet required criteria, two more randomly selected bottles from the same batch are being subjected to burst testing in presence of the inspector. Both of these bottles have to meet prescribed requirements. Otherwise it is necessary to re-heat the whole batch (first annealing, then quenching and tempering).

\section{EXPERIMENTAL PART}

Concerning formability, the impact of manufacturing processes on properties of material is inevitable [10,11]. When forming bottles, this impact is manifested through different properties of the body, the neck and the bottom of the bottle. While the neck and the bottom of the bottle are hot formed from the tube, the body of the bottle remains undeformed.

Experiment plan defines specimens for tensile test: 1) from the bottle before heat treatment ("raw" bottle);

2) from the body of finished bottle, after heat treatment;

3) from the neck of finished bottle after heat treatment.

For testing purposes, one raw bottle (before heat treatment) and one finished bottle (after heat treatment) are selected (Fig. 4).

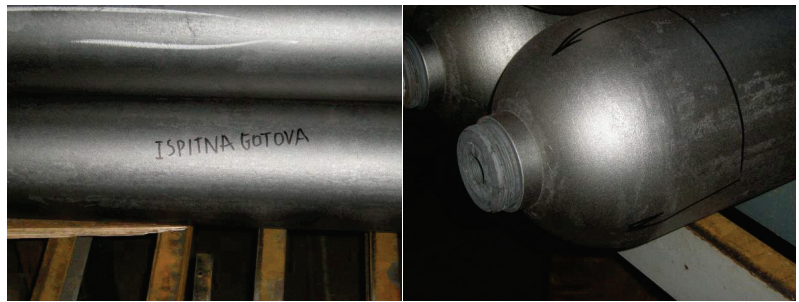

Figure 4 Bottles for test samples

\subsection{Tensile Test Samples}

Dimensional control of wall thickness was performed on samples cut from the body of raw as well as heat treated bottles. The measurement was performed by means of caliper at 15 measuring points approximately $10 \mathrm{~mm}$ 
distanced from each other, Tab. 1. It can be seen that the measured values, both on raw bottle samples as well as finished bottle samples, vary between 6,6 and $6,9 \mathrm{~mm}$.

Table 1 Dimensional control values

\begin{tabular}{|c|c|c|}
\hline \multirow{2}{*}{$\begin{array}{c}\text { Ordinal number of } \\
\text { measurements }\end{array}$} & Raw bottle & Finished bottle \\
\cline { 2 - 3 } & \multicolumn{2}{|c|}{ The wall thickness / s/mm } \\
\hline 1 & 6,9 & 6,7 \\
\hline 2 & 6,8 & 6,6 \\
\hline 3 & 6,6 & 6,9 \\
\hline 4 & 6,6 & 6,7 \\
\hline 5 & 6,8 & 6,7 \\
\hline 6 & 6,9 & 6,8 \\
\hline 7 & 6,8 & 6,8 \\
\hline 8 & 6,8 & 6,7 \\
\hline 9 & 6,8 & 6,6 \\
\hline 10 & 6,7 & 6,7 \\
\hline 11 & 6,8 & 6,9 \\
\hline 12 & 6,8 & 6,6 \\
\hline 13 & 6,8 & 6,7 \\
\hline 14 & 6,6 & 6,8 \\
\hline 15 & 6,7 & 6,7 \\
\hline
\end{tabular}

Fig. 5a shows dimensions of test samples, according to the requirements defined by the standard DIN 50125 [12], in accordance with the nominal thickness of the tube (bottle).

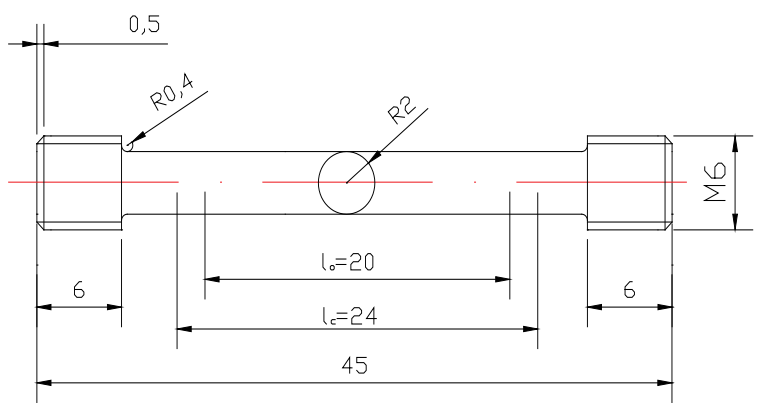

a) Test samples dimensions

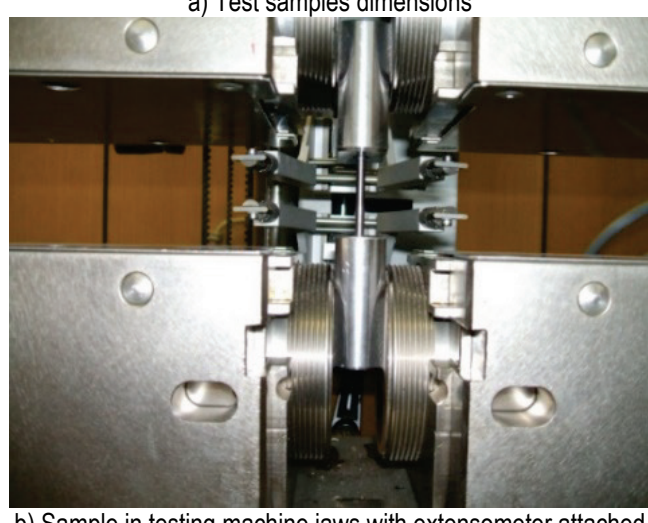

b) Sample in testing machine jaws with extensometer attached Figure 5 Samples for tensile test

\subsection{Results of Tensile Test}

Tensile test was performed on test machine equipped with additional electronics for recording the desired characteristics. Results are showed in Tab. 2.

With respect to dimensions of test samples as well as tightening in testing machine jaws, appropriate adapters have been prepared. Fig. 5b shows the sample in testing machine jaws with extensometer attached. The gauge feelers are connected to computer showing the following test results: force applied, the relative change in length of sample and the plastic flow curves. All tested samples had a gauge length $L_{0}$ of $20 \mathrm{~mm}$, and the cross section area $S_{0}$ of $12,57 \mathrm{~mm}^{2}$. Yield point force and maximal force are recorded and used in calculating conventional yield

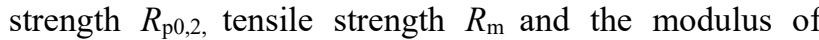
elasticity $E$. Recorded lenghts are used in calculating both elongation $A$ and elongation at maximum force $A_{\mathrm{g}}$.

\begin{tabular}{|c|c|c|c|c|c|c|}
\hline \multirow{2}{*}{$\begin{array}{c}\text { Type of } \\
\text { bottle }\end{array}$} & \multirow{2}{*}{ No. } & $E$ & $R_{\mathrm{p} 0,2}$ & $R_{\mathrm{m}}$ & $A_{\mathrm{g}}$ & $A$ \\
\hline & & $\mathrm{GPa}$ & $\mathrm{MPa}$ & $\mathrm{MPa}$ & $\%$ & $\%$ \\
\hline \multirow{5}{*}{$\begin{array}{l}\text { Body of raw } \\
\text { bottle }\end{array}$} & 1 & 200,4 & 640,99 & 911,24 & 5,55 & 13,91 \\
\hline & 2 & 151,7 & 685,51 & 919,52 & 5,50 & 14,37 \\
\hline & 3 & 176,3 & 626,09 & 875,69 & 5,21 & 14,08 \\
\hline & 4 & 177,6 & 630,32 & 892,59 & 5,89 & 13,78 \\
\hline & 5 & 174,2 & 650,55 & 910,21 & 4,91 & 12,00 \\
\hline \multirow{5}{*}{$\begin{array}{c}\text { Body of } \\
\text { quenched } \\
\text { and tempered } \\
\text { bottle }\end{array}$} & 1 & 200,7 & 956,80 & 1049,39 & 5,67 & 16,73 \\
\hline & 2 & 195,6 & 940,97 & 1028,35 & 5,03 & 15,03 \\
\hline & 3 & 204,3 & 972,71 & 1065,05 & 5,65 & 16,48 \\
\hline & 4 & 200,1 & 949,00 & 1037,21 & 4,83 & 12,77 \\
\hline & 5 & 203,0 & 962,82 & 1048,89 & 4,78 & 14,44 \\
\hline \multirow{3}{*}{$\begin{array}{c}\text { Neck of } \\
\text { quenched } \\
\text { and tempered } \\
\text { bottle }\end{array}$} & 1 & 200,9 & 943,51 & 1029,34 & 4,83 & 15,14 \\
\hline & 2 & 195,5 & 942,67 & 1034,90 & 6,01 & 16,74 \\
\hline & 3 & 204,6 & 961,07 & 1052,77 & 5,38 & 15,43 \\
\hline
\end{tabular}

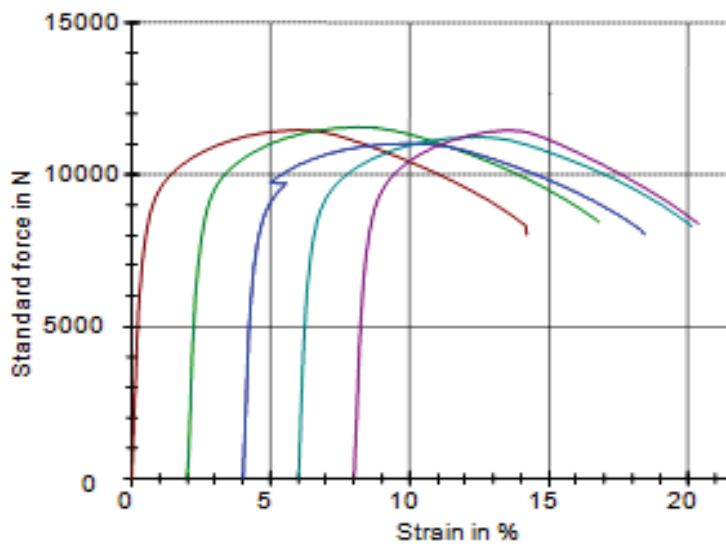

a) Test samples made from the raw bottle

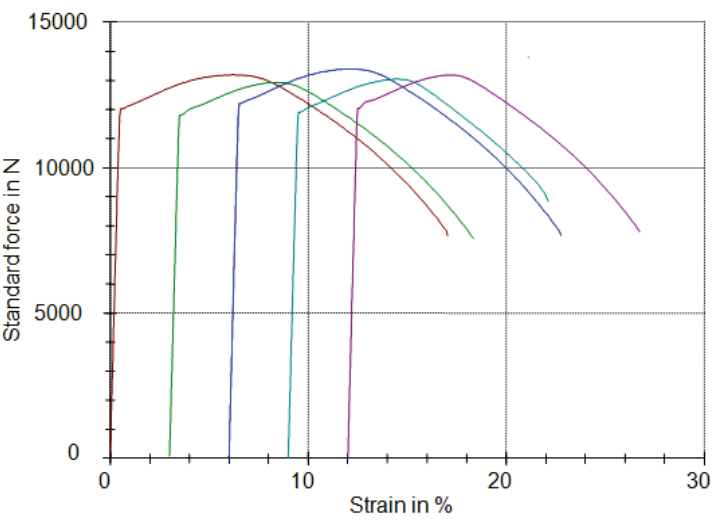

b) For samples made from the quenched and tempered bottle Figure 6 Original diagram of tensile test

Original flow curves of 5 test samples made from raw bottle are shown in Fig. 6a. Flow curves of 5 test samples made from body of quenched and tempered bottle are shown in Fig. 6b.

Yield strength of a raw bottle body is approximately $650 \mathrm{MPa}$ (on average) while tensile strength is approximately $900 \mathrm{MPa}$. Modulus of elasticity is $1,75 \times 10^{5}$ $\mathrm{MPa}$ approximately. Relative elongation at break varies between $12 \%$ and $14,4 \%$ approximately. Elongation at 
maximal force varies between $4,9 \%$ i $5,5 \%$. Used steel exhibits high strength values $\left(R_{\mathrm{p} 0,2}\right.$ i $\left.R_{\mathrm{m}}\right)$ and low deformation values $\left(A\right.$ i $\left.A_{\mathrm{g}}\right)$ typical for brittle materials. Ratio $R_{\mathrm{p}} / R_{\mathrm{m}} \approx 0,7$ indicates significant deformation hardening. Plasticity is relatively low with manifested tendency towards localized deformations, as shown in Fig. 7a. Localized deformation process starts at a deformation lesser than half of the total elongation, thus this process lasts longer than the first phase of deformation until maximal tensile force is reached.

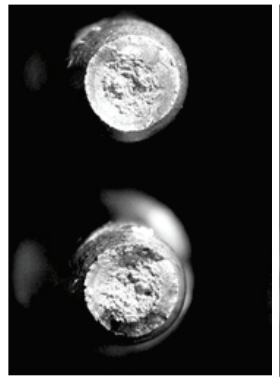

a) Raw body

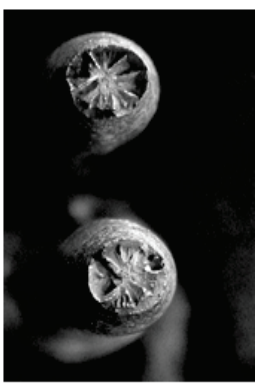

b) QT body
Figure 7 Fracture surface of tested samples

Steel specimens sampled from quenched and tempered tube achieve significantly higher values of yield strength (950 $\mathrm{MPa}$ approximately) which indicates increase of 46,1\%. Similarly, tensile strength also achieves higher values (1050 MPa approximately) which indicates increase of $16,7 \%$. Effect of deformation hardening corresponds to this, it is less pronounced and has a linear character. Plasticity has not decreased while fracture deformation has increased $(12,8 \%$ to $16,7 \%)$. Deformation at maximal force remains the same $(4,8 \%$ to $5,7 \%)$, showing similar tendency towards localized deformation that prevails in plastic deformation zone, Fig. 6b. Localized deformation still remains dominant, Fig. 7b. Also here, deformation hardening has almost a linear character.

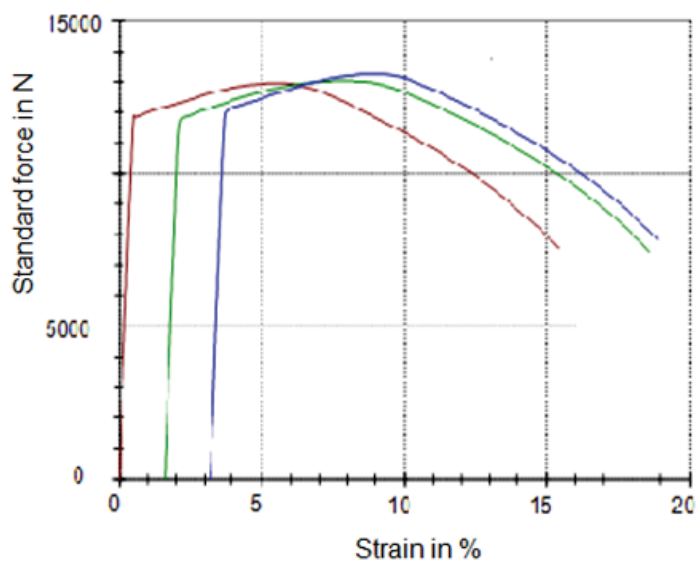

Figure 8 Original diagrams for tearing test samples made from neck of enhanced bottles

Compared to the samples of quenched and tempered bottle body, quenched and tempered bottle neck samples indicate that characteristics of strength are almost unchanged. Results of tensile test of samples made from the neck of the bottle are shown in Fig. 7. For quenched and tempered bottle neck samples it can be said that strength values are approximately the same as those from the samples of quenched and tempered bottle body. It can be noted that minimal fracture deformation has increased from $12,8 \%$ to $15,1 \%$. Local deformation is still dominant, as shown in Fig. 7, while, according to diagram in Fig. 8, it can be concluded that in this case hardening has almost linear character.

\section{RESULT ANALYSIS}

The study determined that steel 34CrMo4 taken out of the raw bottle (tested in the delivered state) has a yield strength of $650 \mathrm{MPa}$ approximately (average value) and tensile strength of $900 \mathrm{MPa}$ approximately. Modulus of elasticity is approximately $1,75 \times 10^{5} \mathrm{MPa}$. Relative elongation at break is in $12 \%$ to $14,37 \%$ range. Elongation at maximum force is in $4,91 \%$ to $5,55 \%$ range.

Plasticity is relatively low with tendency to local deformations. Process of local deformation begins at deformation less than half the total elongation at break, which, according to this, lasts longer than the first phase of deformation until the maximum tensile force is reached (Fig. 6a)

Quenched and tempered samples of bottle body demonstrate significantly higher yield strength compared to raw condition and reach a $950 \mathrm{MPa}$ value. Tensile strength is also increased compared to raw condition and reaches a $1050 \mathrm{MPa}$ value.

Strengthening curve approximation is:

$k_{\mathrm{f}}=\frac{k_{\mathrm{m}}}{\varphi_{\mathrm{m}}^{\varphi_{\mathrm{m}}}} \varphi^{\varphi_{\mathrm{m}}}, \mathrm{MPa}$

Natural deformation at maximum force is calculated by the Eq. (2):

$\varphi_{\mathrm{m}}=\ln \frac{l_{\mathrm{m}}}{l_{0}}$, or $\varphi_{\mathrm{m}}=\ln \left(\frac{A_{\mathrm{g}}}{100}+1\right)$

Deformation strength (equivalent stress) at maximum force is calculated according to the Eq. (3):

$k_{\mathrm{m}}=R_{\mathrm{m}} \cdot \mathrm{e}^{\varphi_{\mathrm{m}}}, \mathrm{MPa}$

Principle of calculating $k \mathrm{i} \varphi_{\mathrm{m}}$ is shown in results recorded by tensile test of sample made from body of raw bottle (first curve in diagram in Fig. 6a, results in first line of Tab. 3):

- $\quad$ the elongation at maximum force: $A_{\mathrm{g}}=5,55 \%$ and $R_{\mathrm{m}}$ $=911,24 \mathrm{MPa}$.

- $\quad$ substituting these values into the Eq. (2) the value of the natural strain at maximum force $\varphi_{\mathrm{m}}=0,054$ is obtained. - substituting these values into the Eq. (3) the final expression for the deformation strength (equivalent stress) at maximal force: $k_{\mathrm{f}}=1126 \varphi^{0,054}, \mathrm{MPa}$ is obtained.

Values of the natural deformation and deformation strength for all other test samples (body of raw bottle, quenched and tempered body of bottle and quenched and tempered neck of bottle) are calculated in the same manner and results are shown in Tab. 3. 


\begin{tabular}{|c|c|c|c|c|c|c|}
\hline Test samples & $\begin{array}{c}\text { Number of the } \\
\text { sample }\end{array}$ & $\begin{array}{c}\text { Tensile strength } \\
R_{\mathrm{m}} / \mathrm{MPa}\end{array}$ & $\begin{array}{l}\text { Relative elongation } \\
\text { at maximum force } \\
\qquad A_{\mathrm{g}} / \%\end{array}$ & $\begin{array}{l}\text { Natural deformation } \\
\text { at maximum force } \\
\qquad \varphi_{\mathrm{m}}\end{array}$ & $\begin{array}{c}\text { Deformation } \\
\text { strength } \\
k_{\mathrm{m}} / \mathrm{MPa}\end{array}$ & $\begin{array}{l}\text { Expression for } \\
\text { deformation } \\
\text { strength } \\
k_{\mathrm{f}} / \mathrm{MPa}\end{array}$ \\
\hline \multirow{5}{*}{ Body of raw bottle } & 1 & 911,24 & 5,55 & 0,054 & 961,80 & $k_{\mathrm{f}}=1126 \varphi^{0,054}$ \\
\hline & 2 & 919,52 & 5,50 & 0,05354 & 970,10 & $k_{\mathrm{f}}=1134,6 \varphi^{0,05354}$ \\
\hline & 3 & 875,69 & 5,21 & 0,05079 & 921,31 & $k_{\mathrm{f}}=1071,86 \varphi^{0,0508}$ \\
\hline & 4 & 892,59 & 5,89 & 0,05723 & 945,16 & $k_{\mathrm{f}}=1113,29 \varphi^{0,05723}$ \\
\hline & 5 & 910,21 & 4,91 & 0,0479 & 954,90 & $k_{\mathrm{f}}=110457 \varphi^{0,0479}$ \\
\hline \multirow{5}{*}{$\begin{array}{l}\text { Quenched and } \\
\text { tempered body of } \\
\text { the bottle }\end{array}$} & 1 & 1049,39 & 5,67 & 0,0551 & 1108,89 & $k_{\mathrm{f}}=1145,9 \varphi^{0,0551}$ \\
\hline & 2 & 1028,35 & 5,03 & 0,04907 & 1080,07 & $k_{\mathrm{f}}=1192,3 \varphi^{0,04907}$ \\
\hline & 3 & 1065,05 & 5,65 & 0,05496 & 1125,23 & $k_{\mathrm{f}}=1319,76 \varphi^{0,0549}$ \\
\hline & 4 & 1037,21 & 4,83 & 0,0472 & 1087,30 & $k_{\mathrm{f}}=1255,83 \varphi^{0,0472}$ \\
\hline & 5 & 1048,89 & 4,78 & 0,0467 & 1099,03 & $k_{\mathrm{f}}=1268,09 \varphi^{0,0467}$ \\
\hline \multirow{3}{*}{$\begin{array}{l}\text { Quenched and } \\
\text { tempered neck of } \\
\text { the bottle }\end{array}$} & 1 & 1029,34 & 4,83 & 0,04717 & 1079,06 & $k_{\mathrm{f}}=1246,3 \varphi^{0,0472}$ \\
\hline & 2 & 1034,90 & 6,01 & 0,0584 & 1097,09 & $k_{\mathrm{f}}=1299,1 \varphi^{0,0584}$ \\
\hline & 3 & 1052,77 & 5,38 & 0,0524 & 1109,40 & $k_{\mathrm{f}}=1294,81 \varphi^{0,0524}$ \\
\hline
\end{tabular}

\section{CONCLUSION}

This paper shows the individual operations specifics with emphasis on those that may directly affect the controled properties of the finnished bottle before delivery.

Results of dimensional control of each sample show wall thickness higher than the calculated and required minimum value of $5,4 \mathrm{~mm}$.

Static tensile test on samples cut from the raw bottle (samples before heat treatment) shows a relative tendency to plastic deformation but a pronounced tendency to local deformation. Quenched and tempered bottle body samples demonstrate a $46,1 \%$ higher yield strength compared to bottles before heat treatment and reach approximately 950 $\mathrm{MPa}$ value. Compared to the situation before quenching and tempering, an increase of approximately $17 \%$ and a value of approximately $1050 \mathrm{MPa}$ can be seen in tensile strength also. The effect of deformation hardening corresponding to this change, is less pronounced and has almost linear character.

Strength properties from the bottle neck cut samples are almost unchanged compared to the samples of quenched and tempered body of the bottle. The minimum amount of deformation at fracture increased from $12,8 \%$ to $15,1 \%$. In this case hardening has an almost linear form. It can be concluded that samples cut from quenched and tempered bottle (after heat treatment) do not have propensity to brittle fracture.

Based on that it can be concluded that the results of mechanical testings i.e. deformation strength calculated on the basis of testing results can be used as indicator of potentially present danger of brittle fractures when conducting bottles bursting test. All afore-mentioned establishes conditions for research continuation in order to further determine the influence of parameters improving the effect of deformation strength and in other cases of one or two ends of tube forming.

\section{REFERENCES}

[1] Kučera, P. \& Mazancová, E. (2015). Mechanical and structural response of AISI 4135 steel after controlled cooling process. Metalurgija, 55(2), 165-169.

[2] Alvino, A., Antonini, A., \& Lega, D. (2014). Failure analysis on a fractured $34 \mathrm{CrMo} 4$ steel high pressure cylinder filled with a mixture of inert gases. Engineering Failure Analysis, 38, 49-57. https://doi.org/10.1016/j.engfailanal.2014.01.004
[3] Sajadi, S. V., Ketabchi, M., \& Nourani, M. R. (2010). Hot Deformation Characteristics of 34CrMo4 Steel. Journal of Iron and Steel Research, 17(12), 65-69. https://doi.org/10.1016/S1006-706X(10)60199-9

[4] Kučera, P. \& Mazancová, E. Relation between the grain size development and mechanical properties Of $34 \mathrm{CrMo} 4$ steel after four types of treatment. Retrieved from: http://konsys2.tanger.cz/files/proceedings/21/papers/4061.p df

[5] F. Nuernberger, F., Grydin, O., Schaper, M., Bach, F.-W., Koczurkiewicz, B., \& Milenin, A. (2010). Microstructure Transformations in Tempering Steels during Continuous Cooling from Hot Forging Temperatures. Steel Research International, 81(3), 224-233. https://doi.org/10.1016/S1006-706X(10)60199-9

[6] Zakon o tehničkim zahtjevima za proizvode i ocjenu sukladnosti, prema: HRN EN ISO 11623,HRN EN 1968, HRN EN 1802, Narodne novine br. 138/08.

[7] BS EN 10083-3:2006 Steels for quenching and tempering. Technical delivery conditions for alloy steels.

[8] http:// www.csc-sb.hr/proizvodni_program.pdf, 03.08.2013.

[9] The Company has certificate ISO 9001, certificate ISO 11439 , and type approvals for finishing of cylinders within production program. Design, finishing and testing www.cscsb.hr/quality_control.html, 02.05.2013.

[10] Djordjević, M., Aleksandrović, S., Vujinović, T., Milentije Stefanović, M., Lazić, V., \& Nikolić, R. (2012). Computer Controlled Experimental Device for Investigations of Tribological Influences in Sheet Metal Forming,Materials Engineering - Materialove inžinierstvo, SK ISSN 13350803, 19, 88-94.

[11] Grizelj, B. (2002). Obrada metala deformiranjem. Sveučilište J. J. Strossmayera, Strojarski fakultet Slavonski Brod.

[12] DIN 50125: Testing of metallic materials - Tensile test pieces Description: Deutsches Institut Fur Normung E. V. (German National Standard), 07-01-2009.

\section{Contact information:}

Vlatko MARUŠıć, PhD, Full Professor

(Corresponding author)

Mechanical Engineering Faculty in Slavonski Brod,

University of JosipJurajStrossmayer in Osijek,

Trg Ivane Brlić Mažuranić 2 ,

35000 Slavonski Brod, Croatia

E-mail: vmarusic@sfsb.hr

Srbislav ALEKSANDROVIć, PhD, Full Professor

Faculty of Engineering,

University of Kragujevac,

Sestre Janjić 6, 34000 Kragujevac, Serbia

E-mail: srba@kg.ac.rs 
Bogdan NEDIĆ, PhD, Full Professor

Faculty of Engineering,

University of Kragujevac,

Sestre Janjić 6, 34000 Kragujevac, Serbia

E-mail: nedic@kg.ac.rs

Andrijana MILINOVIĆ, PhD, Assistant Professor

Mechanical Engineering Faculty in Slavonski Brod,

University of Josip Juraj Strossmayer in Osijek,

Trg Ivane Brlić Mažuranić 2,

35000 Slavonski Brod, Croatia

E-mail: amilinovic@sfsb.hr 